\title{
Preparation and evaluation of lidocaine hydrochloride in cyclodextrin inclusion complexes for development of stable gel in association with chlorhexidine gluconate for urogenital use
}

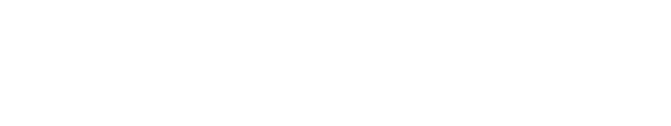

Luiz Francisco Jones Soares da Silva

Flavia Almada do Carmo

Vinicius Raphael de Almeida

Borges

Lidiane Mota Monteiro Carlos Rangel Rodrigues Lúcio Mendes Cabral Valeria Pereira de Sousa

Departamento de Medicamentos, Faculdade de Farmácia, Universidade Federal do Rio de Janeiro, Rio de Janeiro, RJ, Brazil
Correspondence: Valeria Pereira de Sousa Departamento de Medicamentos, Faculdade de Farmácia, UFRJ, Prédio do CCS, Bloco K, $2^{\circ}$ andar, Sala I5, Ilha do Fundão, 2194|-590, Rio de Janeiro, Brazil Tel/Fax +55 2I 25647380

Email valeria@pharma.ufri.br
Abstract: Inclusions of lidocaine hydrochloride in cyclodextrins were prepared to obtain stable complexes compatible for association with chlorhexidine in a new gel formulation for use in urogenital applications. Two cyclodextrins, $\beta$-cyclodextrin and methyl- $\beta$-cyclodextrin, were used for encapsulating lidocaine hydrochloride through solubilization and kneading techniques. The lidocaine-cyclodextrin complexes were characterized by ultraviolet spectroscopy, Fourier transform infrared spectroscopy, differential scanning calorimetry, and X-ray diffraction. The results revealed that the techniques generated good yields of inclusion products that maintained the functional properties of lidocaine. In addition, the inclusion products obtained improved the compatibility of lidocaine hydrochloride with chlorhexidine in solution and a gel formulation. The gel formulation displayed desirable rheological and physicochemical properties. The results presented here are the first description of the inclusion of lidocaine with cyclodextrins, which improves compatibility with chlorhexidine in formulations for simultaneous delivery.

Keywords: solubilization and kneading inclusion techniques, cyclodextrins, lidocaine hydrochloride, chlorhexidine gluconate incompatibility, urogenital gel formulations

\section{Introduction}

The increase in various urogenital procedures, including invasive procedures, has created a need for sterile lubricants that also deliver, simultaneously, a local anesthetic and a bactericide. ${ }^{1-4}$ Yet the availability in the pharmaceutical market of products with these characteristics is still very low. The British National Formulary describes a gel formulation that includes $2 \%$ lidocaine hydrochloride (LID, anesthetic) and $0.25 \%$ chlorhexidine gluconate ( $\mathrm{CHX}$, bactericide) together, which is available commercially. ${ }^{5}$ However, the characteristics of these drugs together show evidence of physicochemical incompatibilities, which suggests that this type of formulation is extremely unstable, unless one or both drugs have been modified to avoid such phenomena. ${ }^{6,7}$

The literature describes several approaches for improving the stability and/or compatibility for different drugs such as solvent selection during formulation and molecular encapsulation processes. ${ }^{8}$ Cyclodextrins (CDs) are commonly used for encapsulation and comprise a series of $\alpha-1,4$-linked cyclic oligosaccharides consisting of $6(\alpha C D)$, 7 ( $\beta C D), 8$ ( $\gamma C D)$, or more glucose units leading to a cup-like geometry. CDs have a rigid structure with a singular hydrophobic cavity due the absence of hydroxyl groups. Due to their distinctive structure, CDs are able to enhance the solubility, chemical stability, and bioavailability of poorly soluble drugs, while reducing toxicity 
and controlling the rate of release. ${ }^{9}$ Moreover, complexing drugs with CD may also: i) enhance drug stability to air and light, ii) affect the availability of topically applied products, either increasing or decreasing their permeability into and through the skin, and iii) delay the beginning of the process of photodegradation. ${ }^{9-11}$ In comparison with other pharmacotechnical approaches, the performance of CDs often displays greater efficacy for stabilizing drugs and bridging drug incompatibilities in various formulations and, in many situations, represents the only alternative.

We investigated the inclusion of LID into CDs to create a new urogenital gel formulation together with $\mathrm{CHX}$ with increased stability and an adequate release profile. Towards that purpose, LID and the CDs $\beta$-cyclodextrin $(\beta C D)$ and methyl- $\beta$-cyclodextrin $(\mathrm{M} \beta \mathrm{CD})$ were tested by using solubilization and kneading techniques. The LID-CD inclusion complexes were characterized and the gel formulated with these complexes was evaluated for the in vitro release of LID from the complex, its rheological properties, and other pharmacotechnical properties for characterization of a new formulation for delivery of an anesthetic together with a bactericide.

\section{Material and methods Materials}

Ethanol (95\%), butylated hydroxyanisole (BHA) and butylated hydroxytoluene (BHT), Nipagim, polyethylene glycol (PEG) 6000, PEG-15 cocopolyamine, and Natrosol were obtained from DEG (São Paulo, Brazil); the CHX standard (20\% w/v) was obtained from Sigma-Aldrich (St Louis, MO); LID was obtained from Nortec Química (Xerém, RJ, Brazil); and $\beta C D$ and $M \beta C D$ were obtained from Wacker-Chemie GmbH (Munchen, Germany) and were of a pharmaceutical grade. The purified water used in all solutions preparations was prepared using a Milli-Q system (Millipore, Billerica, MA).

\section{Drug and formulation analysis}

The concentration of LID and CHX was determined following the protocols outlined by the Brazilian Pharmacopoeia (1998). ${ }^{12}$ Other tests used to assess the quality of raw materials followed the guidelines of the Brazilian and British Pharmacopeia monographs. ${ }^{12,13}$

\section{Apparatus and chromatographic conditions}

A high performance liquid chromatograph (HPLC) model Shimadzu LC-10AT was used. The chromatographic conditions were initially based on a study of simultaneous determination of LID and CHX in a triamcinolone acetonide suspension, using reverse phase HPLC. ${ }^{14}$ During the verification of the best chromatographic conditions to resolve the peaks of each drug using known standards, the mobile phase was varied between $60 \%$ and $65 \%$ of methanol with triethylamine (0.4\%) at $\mathrm{pH} 3.5$ and the detection wavelength was set at $240 \mathrm{~nm}$. Experimental samples were analyzed based on those conditions.

\section{Preparation of standard and sample solution}

A working standard solution of LID and CHX in mobile phase (400 $\mu \mathrm{g} / \mathrm{mL}$ for LID and $50 \mu \mathrm{g} / \mathrm{mL}$ for CHX) was prepared using drug reference standard from US Pharmacopeia that was accurately weighed and transferred into a 50-mL flask. Mobile phase was added to the mixture and sonicated until the standard dissolved completely ( $\sim 5$ minutes). Then the flask was filled with mobile phase and filtered through a $0.45 \mu \mathrm{m}$ membrane filter (Millipore).

For sample preparation, an adequate amount of gel formulation or chemical standard substances were weighed and the amount equivalent to $400 \mu \mathrm{g} / \mathrm{mL}$ of LID and $50 \mu \mathrm{g} / \mathrm{mL}$ for CHX were transferred to a $50 \mathrm{~mL}$ volumetric flask. After that, the preparation followed the same procedure described for the standard solution preparation.

\section{Validation of HPLC quantitative determination of LID and $\mathrm{CHX}$}

In order to validate the analytical method proposed, the measurement parameters were investigated for linearity, accuracy, precision, and specificity according to the International Conference on Harmonization recommendations. ${ }^{15}$

Linearity was tested with a range of concentrations (50\%, 80\%, 100\%, 120\%, and 150\%); 100\% corresponded to a concentration of $400 \mu \mathrm{g} / \mathrm{mL}$ for LID and $50 \mu \mathrm{g} / \mathrm{mL}$ for CHX. A calibration curve was generated and the linearity was evaluated by the calculated correlation coefficient and interception value.

Accuracy was evaluated by analyzing 3 independently prepared samples (spiked placebo) of 3 concentrations ( $80 \%, 100 \%$, and $120 \%$ of the working concentration). Each preparation was measured 3 times. Values between $98 \%$ and $102 \%$ of recovery were considered acceptable.

Precision of the measurement method was determined by evaluating the repeatability and the intermediate precision of measurements on standards. Repeatability was evaluated using 6 replicated samples of a solution containing drugs at a concentration of $100 \%$ of the regular analytical working concentration. ${ }^{15}$ The intermediate precision was judged 
by repeating the procedure on 2 different days. The results obtained were analyzed statistically and a RSD value below $2 \%$ was considered acceptable.

Specificity was determined with Class VP software, which calculated the peak purity by ratiogram. The specificity was further analyzed by comparing the chromatograms of the various formulations to the placebo chromatogram for evidence of interference from the formulation matrix on the measurements.

\section{Formulation of LID and CHX gel formulations}

Initially, LID and CHX were prepared in a range of ethanol solutions $(10 \%, 30 \%, 50 \%, 70 \%$, and $90 \%)$ to obtain final concentrations of $2.0 \% \mathrm{w} / \mathrm{v}$ for LID and $0.25 \% \mathrm{w} / \mathrm{v}$ for CHX. Complete solubilization of the drugs was observed. The compatibility of the 2 drugs was evaluated by maintaining solutions in a $10-\mathrm{mL}$ beaker under magnetic stirring for 0 , 5, 30, and 60 minutes, and 24 hours and observing turbidity. The presence of white precipitate was considered evidence of incompatibility.

The gel formulation preparation was initiated by choosing the ideal excipients based on compatibility with the drugs, especially for CHX. The tests for the carrier solutions were performed according to the procedures described above with a concentration of $0.25 \% \mathrm{w} / \mathrm{v}$ for CHX. After the compatible excipient was determined, the gel was formulated by adding methylparaben and BHA to a final concentration of approximately $40 \% \mathrm{w} / \mathrm{v}$ under magnetic stirring. Then, PEG-15 cocopolyamine was added to a concentration of $2 \%$. After incorporation, hydroethylcellulose (4\%) and the remaining water were added. This mixture was kept under magnetic stirring until complete gelation of the polymer and a final gel that was mostly clear with a slight yellow tint due to the presence of hydroxyethylcellulose and PEG-15 cocopolyamine. For a gel containing ethanol, BHA was substituted with BHT at the same concentration.

\section{Preparation of LID-CDs complexes through the solubilization method}

To establish the optimal ratio of LID with $\beta C D$ and $M \beta C D,{ }^{16-18}$ stock solutions of the CDs $(1.15 \mathrm{~g}$ diluted in $100 \mathrm{~mL}$ of purified water) and LID (50 mg dissolved in $5 \mathrm{~mL}$ solvent) were prepared separately. LID was then added to the vessels containing the $\mathrm{CD}$ solution (qs $20 \mathrm{~mL}$ ) in volumes necessary to reach various $\mathrm{CD}$ :drug molar ratios $(2: 1,3: 1,4: 1,5: 1,6: 1$, and 7:1). For control purposes, a "0" point including only the original LID solution without CD was also prepared.
All mixtures were stirred for 72 hours at $25^{\circ} \mathrm{C}$ followed by a time without stirring to allow precipitates to settle, and then decanted through Whatman 42 analytical paper. If no additional precipitate was observed, the inclusion products were frozen at $-70^{\circ} \mathrm{C}$ and lyophilized for further analysis.

\section{Inclusion of LID into CDs by kneading method}

The calculated amounts of drug and corresponding CD were weighed, and moistened with a small volume $(1 \mathrm{~mL})$ of ethanol:water solution $(70: 30, \mathrm{v} / \mathrm{v})$. The mixtures were grounded using a ball mill until the mixture reached a granulation aspect. ${ }^{16}$ The resulting product was further mixed for 30 minutes. The final samples were dried in an oven at $55^{\circ} \mathrm{C}$ for 30 minutes and stored in desiccators.

\section{Characterization of the inclusion complexes}

The concentrations of LID in the CD complex were determined by using an UV spectrometer (Perkin-Elmer, Norwalk, CT). The concentrations in the calibration curve were 2.0, 4.0, 6.0, 8.0, 10.0, and $12.0 \mu \mathrm{g} / \mathrm{mL}$ for LID, with $R^{2}$ values between 0.995 and 0.998 in all of the studied cases. Fourier transformed infrared spectra for all samples were recorded using $\mathrm{KBr}$ pellets ( $1 \mathrm{mg}$ sample per $300 \mathrm{mg} \mathrm{KBr}$ ) on a Perkin-Elmer FT-IR Spectrometer Paragon 1000 grating instrument with slow scan and normal slit width: X-ray diffraction patterns of the drug-CD inclusion complex were obtained by using an X-ray Diffractometer (XRD; Rigaku, Tokyo, Japan). The diffraction angle $(2 \theta)$ of the patterns was recorded from $2^{\circ}$ to $10^{\circ}$ at $1 \% \mathrm{~min}$, with a total scanning speed of 41 minutes. $\mathrm{CuKa}$ radiation was used as the $\mathrm{X}$-ray source, which was operated at $40 \mathrm{kV}$ and $30 \mathrm{~mA}$ at room temperature and $0.15418 \mathrm{~nm}$ wavelength. Differential scanning calorimeter analysis was performed from $0^{\circ} \mathrm{C}$ to $400^{\circ} \mathrm{C}\left(10^{\circ} \mathrm{C} / \mathrm{min}\right)$ with a Perkin-Elmer DSC 7 in an aluminum pan under a nitrogen flow $(22.5 \mathrm{~mL} / \mathrm{min})$.

\section{Stability studies}

The stability of the prepared gels was determined using each of the analytical methodologies previously described for the drug assays and also included $\mathrm{pH}$ and rheological proprieties. Samples were stored under $30 \pm 2{ }^{\circ} \mathrm{C}$ and $75 \% \pm 5 \% \mathrm{RH}$ for 30,60 , and 90 days. The $\mathrm{pH}$ of the samples was determined using a Digimed DM21 potentiometer. The rheological study was performed to obtain the physical parameters such as flow index, consistency index, apparent viscosity and thixotropy. Rheological measurements were obtained in an Advanced 
Rheometer (TA Instruments, New Castle, DE), model 2000, which is a cone and plate viscosimeter with a $60 \mathrm{~mm}$ cone and a $2^{\circ}$ determination angle. Samples $(3.0 \mathrm{~g})$ were placed on the hot plate at $37^{\circ} \mathrm{C}$ and the cone rotates under adjustable speeds.

\section{In vitro drug release analysis}

The release of LID from the CD complexes and the gel formulation was evaluated in vitro using a modified apparatus based on the Franz Cell concept. ${ }^{19,20}$ An acetate cellulose membrane was mounted on a diffusion system and a sample containing $200 \mathrm{mg}$ of LID was introduced into the donor compartment. Sink conditions were met in all cases and 6 parallel determinations were performed at $37 \pm 0.5^{\circ} \mathrm{C}$. Aliquots of the acceptor solution were withdrawn after 5, 20, $40,60,90,120,180,240,300$, and 360 minutes. A volume of medium equal to that withdrawn was added back following each sampling. The collected fractions were filtered through a $0.45-\mathrm{mm}$ membrane and the filtrate was analyzed by HPLC to quantify the amount of drug diffused into the acceptor solution using a standard curves with a range of $10 \%$ to $110 \%$ prepared in the same day.

The cumulative amount of drug released through the membrane was plotted as a function of time. The flux values $(J)$ was calculated from the slopes of the linear portion (steady state) of in vitro release curves. Release kinetics were determined by linear regression analysis by applying 3 models: zero order, Higuchi, first order, and Peppas.

\section{Statistical data analysis}

One-way ANOVA and Wilcoxon match pair tests were used to analyze all of the data obtained.

\section{Results and Discussion \\ Methods development and optimization}

The isocratic-mode method with UV detection applied in this study was developed for the determination of the active ingredients, LID and CHX, at the 100\% level, and its main degradation products, $p$-chloroaniline and 2,6-dimethylaniline. Towards that purpose, a reversed-phase column $\mathrm{C}_{18}(250 \mathrm{~mm}$, $4.0 \mathrm{~mm} ; 5.0 \mu \mathrm{m}$ ) was used and tested with mobile phases consisting of methanol concentrations of $60 \%, 62 \%, 63 \%$, and $65 \%$ with $0.4 \%$ triethylamine solutions at various ratios $(65: 35 ; 63: 37 ; 62: 38$, and $60: 40, \mathrm{v} / \mathrm{v})$. The variation in the methanol concentration of the mobile phase significantly modified the CHX retention time, but not the LID retention time, which remained mostly unchanged. An increase in the methanol concentration from $60 \%$ to $65 \%$ in the mobile phase decreased the $\mathrm{CHX}$ retention time from 14.5 to 6.4 minutes.
The addition of triethylamine to the mobile phase generated an improved symmetry of the observed chromatographic peaks for both drugs without an alteration in the retention time or the separation of the peaks. Variations in the $\mathrm{pH}$ of the mobile phase from 3.0 to 4.0 did not significantly alter the drug retention time, but affected the shape of the peak for CHX. By comparing the chromatographic behavior as peak retention times, theoretical plates, capacity, and tailing factors, the chromatographic conditions described in Table 1 were considered ideal. Under the preferred conditions, LID displayed a retention time of 4.4 minutes, a theoretical plate of 3961, and an asymmetry of 1.66. For CHX, the retention time was 10.1 minute with a theoretical plate of 6707 and an asymmetry of 1.47 . The literature described similar results from the analysis of another gel formulation, but with different excipients. ${ }^{14}$

\section{Method validation}

The selectivity of the assay method for the drug determination and for the presence of $\mathrm{CHX}$ degradation products ( $p$-chloroaniline and 2,6-dimethylaniline) in the formulation was accessed by individual chromatograms obtained for each drug with the formulation matrix and revealed an adequate peak purity for the drugs (Figure 1).

The linearity was determined using 5 samples in different concentrations between $50 \%$ and $150 \%$ from the nominal assay concentration of $400 \mu \mathrm{g} / \mathrm{mL}$ for LID and $50 \mu \mathrm{g} / \mathrm{mL}$ for CHX standard. This procedure was carried out on 2 different days in agreement to the $\mathrm{ICH} .{ }^{15} \mathrm{~A}$ calibration curve was constructed to calculate the correlation coefficient and intercept value, which was evaluated using a statistic study (ANOVA) and determined to be significant $(P<0.05)$. The regression equation was obtained by a least squares treatment of the data and the results confirmed the linearity of the data from the method developed (Table 2). The homoscedasticity of the

Table I Chromatographic analysis conditions for chlorhexidine gluconate $(\mathrm{CHX})$ and lidocaine hydrochloride (LID)

\begin{tabular}{ll}
$\begin{array}{l}\text { Chromatographic } \\
\text { conditions }\end{array}$ & Specifications \\
\hline Column & Shim-pack CLC - ODS $250 \times 4.6 \mathrm{~mm}, 5 \mu \mathrm{m}$ \\
Elution & Isocratic \\
Mobile phase & $63: 37$ \\
& Methanol; purified water with triethylamine \\
& $0.4 \% ; \mathrm{pH} 3.5$ \\
Flow & $0.8 \mathrm{~mL} / \mathrm{min}$ \\
Run time & $20 \mathrm{~min}$ \\
Wavelength $(\lambda)$ & $240 \mathrm{~nm}$ \\
Injection volume & $20 \mu \mathrm{L}$ \\
Diluent & Mobile phase \\
Temperature & Room temperature \\
\hline
\end{tabular}

Abbreviations: CLC-ODS, Capillary liquid chromatography-octadecylsilane 

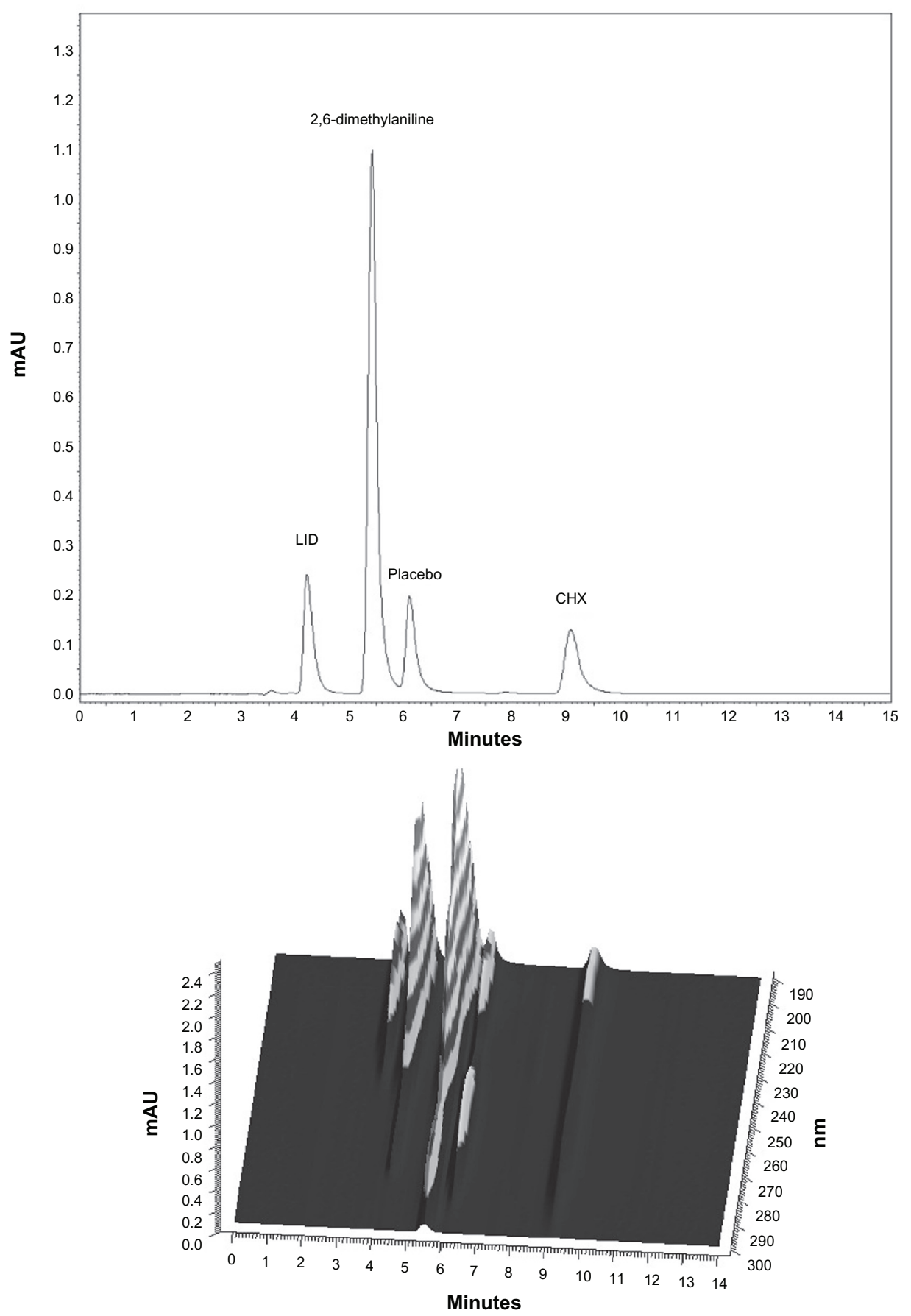

Figure I Chromatograms of placebo contaminated with LID, CHX, and degradation products ( $p$-chloroaniline and 2,6-dimethylaniline) A) and the respective 3D UV/Vis spectra B).

Abbreviations: $\mathrm{CHX}$, chlorhexidine gluconate; LID, lidocaine hydrochloride.

calibration curves was tested using Cochran's test $(\mathrm{G}=$ largest variance/sum of variances).$^{21}$ The $\mathrm{G}$ value obtained in this study (0.419) was smaller than the critical value $(G=0.684)$, indicating that variances were not significantly different.

The accuracy was evaluated by the recovery of CHX and LID at 3 different levels $(80 \%, 100 \%$, and $120 \%)$, tested 3 times. The individual recoveries ranged from $99.6 \%$ to
$100.4 \%$ for LID and $98.1 \%$ to $100.7 \%$ for CHX with an $\mathrm{RSD}<1.5 \%$ in both cases. Therefore, these results indicate the accuracy of the method for determination of both drugs.

The reproducibility of the methods was confirmed by analyzing 3 sample replicates on the same equipment with a concentration that ranged from $80 \%$ to $120 \%$ of the analytical concentration $(100 \%)$. The intermediate precision was 
Table 2 Summary data of linearity for HPLC method

\begin{tabular}{llc}
\hline Parameters & LID & CHX \\
\hline Slope (b) & $7015394 \pm 17427.4$ & $54433871 \pm 617649.2$ \\
Intercept (a) & $191754.5 \pm 1727.5$ & $-285845 \pm 4358.6$ \\
$r$ & $0.99925 \pm 0.00007$ & $0.9975 \pm 0.0004$ \\
\hline
\end{tabular}

Note: Media \pm standard deviation of $n=2$ determinations.

Abbreviations: $\mathrm{CHX}$, chlorhexidine gluconate; LID, lidocaine hydrochloride.

determined by performing the analysis on 2 different days. The data presented in Table 3 show that the method has a good repeatability and intermediate precision.

The detection limit was $2.7 \mu \mathrm{g} / \mathrm{mL}$ for LID and $0.6 \mu \mathrm{g} / \mathrm{mL}$ for CHX, while the quantification limit was $9.0 \mu \mathrm{g} / \mathrm{mL}$ for LID and $2.1 \mu \mathrm{g} / \mathrm{mL}$ for CHX. These values were calculated using calibration curves generated from a range of concentrations between $50 \%$ to $150 \%$ of each drug (200 to $600 \mu \mathrm{g} / \mathrm{mL}$ for LID and 25 to $75 \mu \mathrm{g} / \mathrm{mL}$ for $\mathrm{CHX}$ ).

\section{$\mathrm{CHX}$ and LID gel formulation development}

Initially, the compatibility of CHX and LID together in solution was investigated. CHX and LID are known to be incompatible in the presence of different ions and hydrochlorides leading to precipitation and degradation, but unknown in a simple hydroalcoholic solution. The result of degradation is the formation of various amounts of $p$-chloroaniline, which was described previously. ${ }^{6,22,23}$ Ethanol was chosen as the solvent because of its utilization in various gels formulas. The increase of ethanol in the mixture up to $75 \%$ did not prevent the precipitation. An immediate precipitation was observed when using $0.5 \%$ ethanol and, with a delay up to 24 hours, when using $95 \%$ ethanol. Therefore, even in a less polar solvent, which effectively dissolved less LID, incompatibility between the drugs was observed. This observation contradicts the report by Abdelmageed and Colleagues ${ }^{24}$ which described a stable relationship within a formulation (trade name Instilliagel ${ }^{\circledR}$ ) with morphine sulfate, which was prepared for clinical studies. ${ }^{24}$ Our results demonstrating an incompatibility between LID and CHX in solvents normally capable of dissolving the drugs individually suggested the need for an alternative approach to prevent the formation of precipitate and a break-down of the drugs.

The alternative approach was to complex one of the drugs into CDs. LID was chosen since it is less soluble and smaller then $\mathrm{CHX}$, increasing the chance of a total inclusion into the CD cavity. The inclusion of CHX and LID into CD has been previously described, but only for the free base and not for the salt forms of these drugs. ${ }^{25,26}$ To complex the salt form of LID, $\beta C D$ and $M \beta C D$ were investigated for their ability to form LID inclusion complexes. The stability constant of the inclusion complex was determined by solubilization method with different concentration of CDs, emphasizing that LID solution absorbance is near to zero, differentiating the inclusion complex obtained. The correlation between the observed absorbance depended on the concentration of $\beta C D$ added to the LID that was previously solubilized in the medium and was linear with a correlation coefficient of 0.9996 . The

Table 3 Summary data of repeatability and intermediate precision

\begin{tabular}{|c|c|c|c|c|c|c|c|}
\hline \multirow[b]{2}{*}{$\begin{array}{l}\text { Level } \\
\text { (\%) }\end{array}$} & \multirow[b]{2}{*}{ Day } & \multicolumn{3}{|l|}{ LID } & \multicolumn{3}{|l|}{ CHX } \\
\hline & & Area & $\begin{array}{l}\text { Repeatability } \\
\text { RSD (\%) }\end{array}$ & $\begin{array}{l}\text { Intermediate } \\
\text { precision RSD (\%) }\end{array}$ & Area & $\begin{array}{l}\text { Repeatability } \\
\text { RSD (\%) }\end{array}$ & $\begin{array}{l}\text { Intermediate } \\
\text { precision RSD (\%) }\end{array}$ \\
\hline \multirow[t]{6}{*}{80} & 1 & 2761547 & 0.94 & 1.61 & 2049852 & 1.65 & 1.76 \\
\hline & & 2813985 & & & 2079847 & & \\
\hline & & $278745 I$ & & & 2012487 & & \\
\hline & 2 & 2683619 & 1.35 & & 1974800 & 1.36 & \\
\hline & & $274424 I$ & & & 2015078 & & \\
\hline & & 2749893 & & & 2026612 & & \\
\hline \multirow[t]{6}{*}{100} & 1 & 3102148 & 0.45 & 1.39 & 2493331 & 0.51 & 0.35 \\
\hline & & 3085497 & & & 2518528 & & \\
\hline & & 3074812 & & & 2502487 & & \\
\hline & 2 & 3108475 & 1.47 & & 2496134 & 0.19 & \\
\hline & & 3195874 & & & 2501924 & & \\
\hline & & 3125489 & & & 2505560 & & \\
\hline \multirow[t]{6}{*}{120} & 1 & 3708974 & 1.22 & I.II & $298|97|$ & 0.47 & 1.22 \\
\hline & & 3694751 & & & 2993257 & & \\
\hline & & $362487 \mid$ & & & 2965487 & & \\
\hline & 2 & 3648719 & 1.19 & & 2895748 & 0.88 & \\
\hline & & 3619875 & & & 2930154 & & \\
\hline & & 3705481 & & & 2945817 & & \\
\hline
\end{tabular}

Abbreviations: $\mathrm{CHX}$, chlorhexidine gluconate; LID, lidocaine hydrochloride; RSD, Relation Standard Deviation. 
A

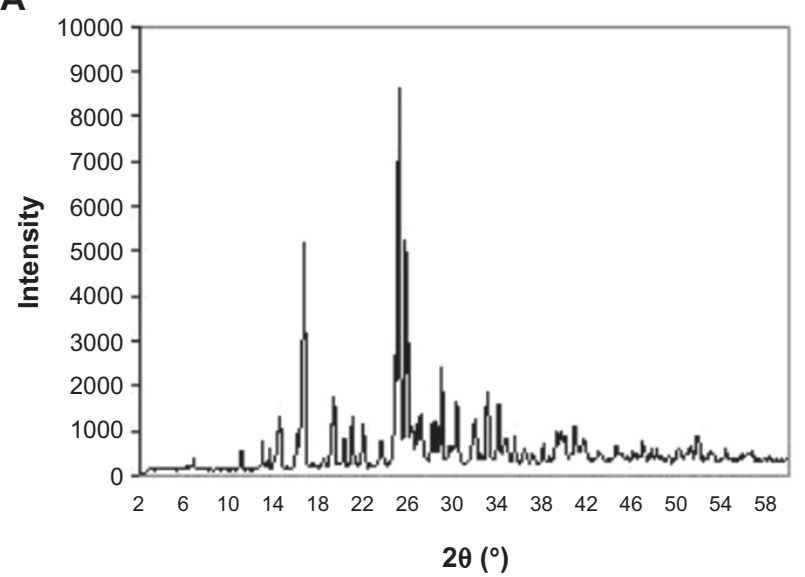

C

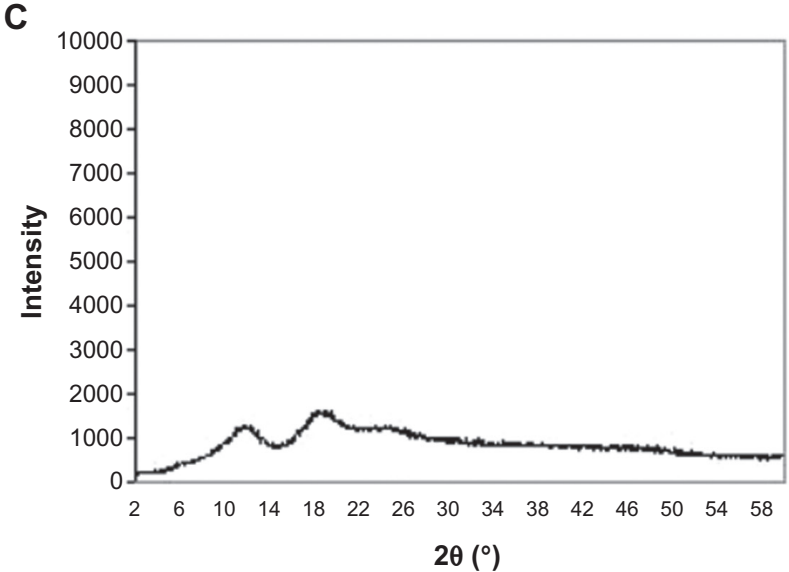

B

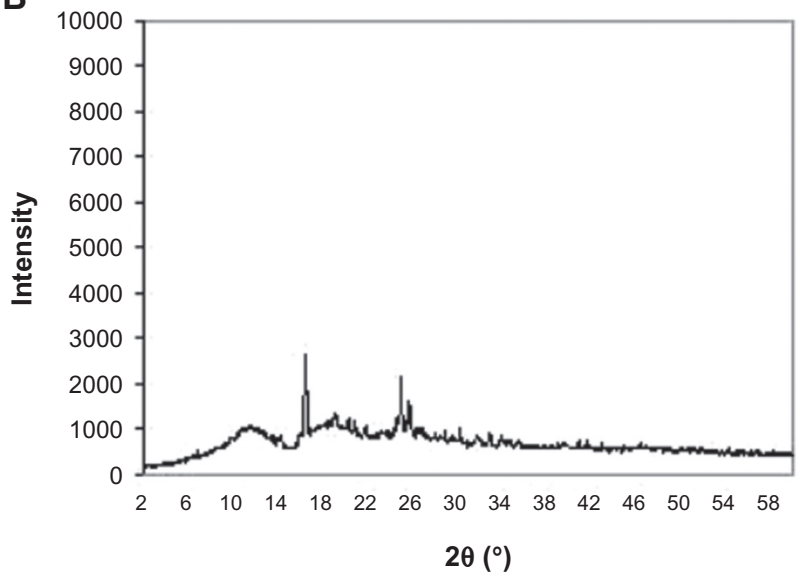

D

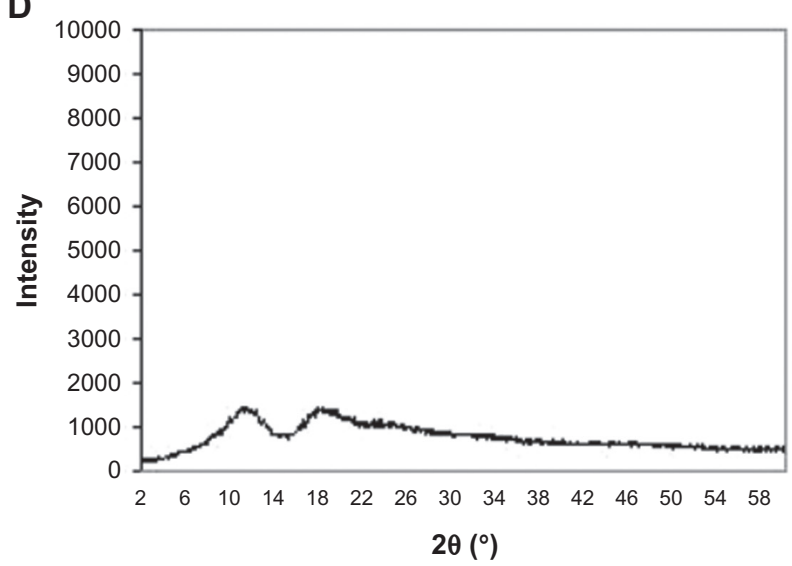

Figure 2 Diffractograms of LID A), physical mixture I:I B), inclusion complex of LID-M $\beta C D$ C), and M $\beta C D$ D). Abbreviations: $M \beta C D$, methyl- $\beta$-cyclodextrin; $\mathrm{CHX}$, chlorhexidine gluconate; LID, lidocaine hydrochloride.

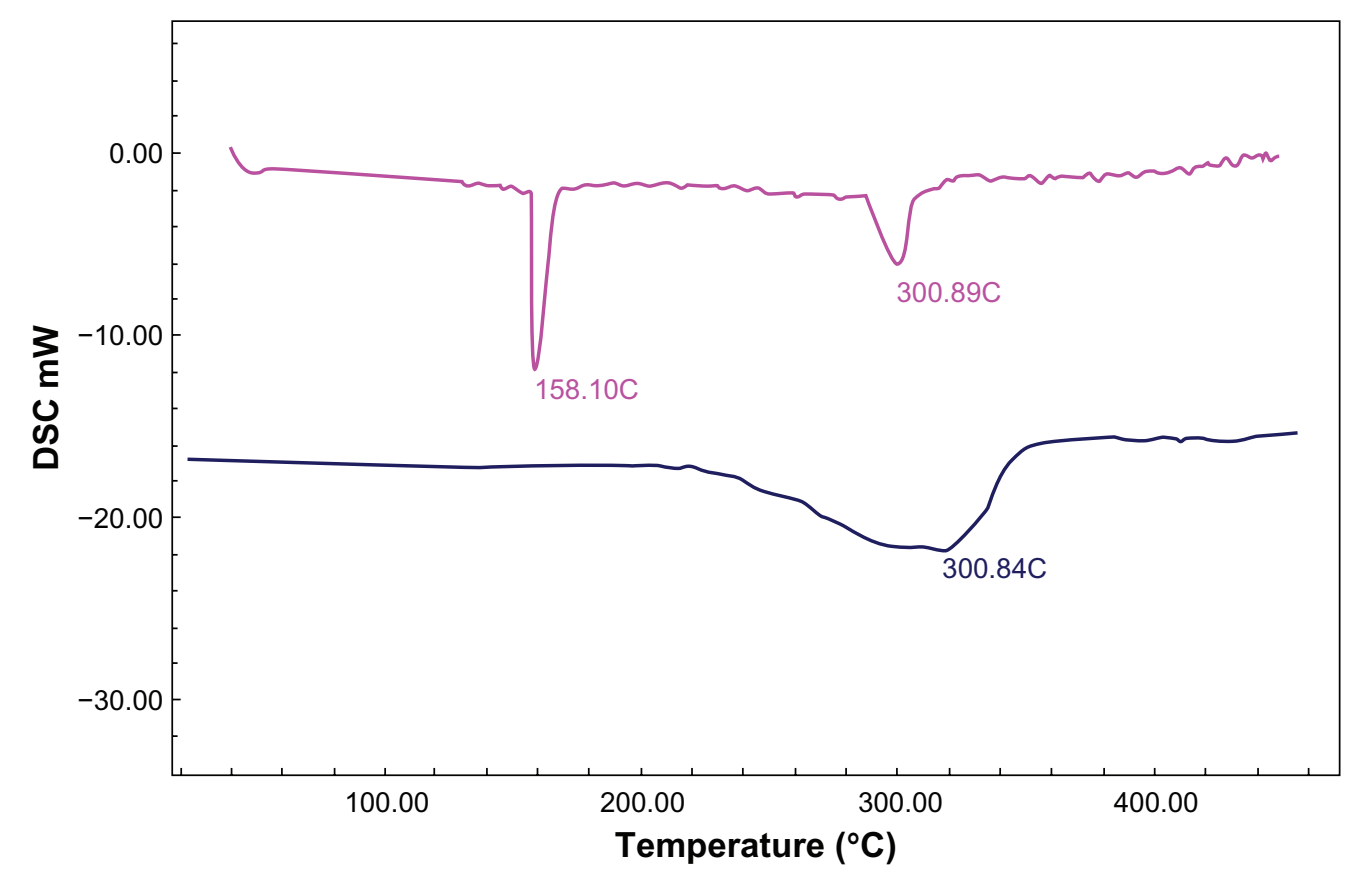

Figure 3 DSC thermogram of M $\beta C D$ (in pink) and the inclusion complex LID-M $\beta C D$ I:I (in blue). Abbreviations: LID, lidocaine hydrochloride; $M \beta C D$, methyl- $\beta$-cyclodextrin. 
Table 4 Results of the compatibility study of free drugs in aqueous media comparing inclusion complexes during 10 days

\begin{tabular}{|c|c|c|c|}
\hline Parameter & Drug free & $\begin{array}{l}\mathrm{CHX}+ \\
\text { LID- } \beta C D\end{array}$ & $\begin{array}{l}\mathrm{CHX}+ \\
\text { LID-MB } \beta C D\end{array}$ \\
\hline Turbidity & Present $^{\mathrm{a}}$ & Absent & Absent \\
\hline Precipitation & Present $^{\mathrm{a}}$ & Absent & Absent \\
\hline $\begin{array}{l}\text { Content of } \mathrm{CHX} \\
\text { mean } \pm \mathrm{SD} \\
(\mathrm{g} / 100 \mathrm{~mL})\end{array}$ & $0.015 \pm 0.0007$ & $0.258 \pm 0.001$ & $0.259 \pm 0.003$ \\
\hline $\begin{array}{l}\text { Content of LID } \\
\text { mean } \pm S D \\
(g / 100 \mathrm{~mL})\end{array}$ & $1.933 \pm 0.005$ & $1.944 \pm 0.01$ & $1.970 \pm 0.02$ \\
\hline
\end{tabular}

Note: ${ }^{a}$ Turbidity and precipitation in solution occurred in about 5 minutes. Study performed at room temperature.

Abbreviations: $\beta C D, \beta$-cyclodextrin; $C D$, cyclodextrin; $C H X$, chlorhexidine gluconate; LID, lidocaine hydrochloride; $M \beta C D$, methyl- $\beta$-cyclodextrin; SD, standard deviation.

calculated stability constant (K) of the complexed LID with $\beta C D$ was $34954.1 \pm 995.4 \mathrm{M}^{-1}$. For the solution using $\mathrm{M} \beta \mathrm{CD}$, the correlation absorbance concentration was also linear with a coefficient of 0.9955 . The calculated stability constant of the complex LID-M $\beta C D$ was $5565.3 \pm 819.9 \mathrm{M}^{-1}$. These values are considered high compared with those previously reported, indicating a stabile complex of LID with both $\beta C D$ and $\mathrm{M} \beta \mathrm{CD} .{ }^{27}$ Despite the variations observed, the water solubility observed for both complexes indicates their feasibility in formulating theses complexes as gels at a concentration of $2.0 \% \mathrm{w} / \mathrm{w}$, which translates to values of $24.95 \mathrm{mg} / \mathrm{mL}$ for LID- $\beta C D$ and $131.56 \mathrm{mg} / \mathrm{mL}$ for LID-M $\beta C D$ at room temperature. The solubility of the inclusion complexes in aqueous medium was lower than LID alone $(166.4 \mathrm{mg} / \mathrm{mL})$, which can be seen with the inclusion of very water soluble molecules ${ }^{26,28-30}$ In ethanol, the extent of solubility observed ruled out the possibility of obtaining gel formulations of $2.0 \%$ $\mathrm{w} / \mathrm{w}$ for the molecules under study.

The kneading process was also attempted for the inclusion of LID with CDs due to the industrial feasibility of this technique. From the experimental determination of the stability constants, LID was included into $\beta C D$ and $M \beta C D$ at a 1:1 CD:drug ratio. The kneading method is described in the literature as an easy procedure, with low cost and high reproducibility. ${ }^{11}$ Using this technique, the results showed a successful inclusion process with about $100 \%$ yield for $\beta C D$ and $M \beta C D$ as measured by LID extraction and HPLC analysis.

The XRD patterns of LID demonstrated that the physical mixtures and inclusion complexes in $\beta C D$ and $M \beta C D$ had a progressive loss of crystallinity in the complex, which demonstrated the phenomenon of inclusion (Figure 2). The infrared analysis of the inclusion products showed LID present in the sample. However the infrared spectra of inclusion complex and physical mixture were quite similar. The major difference was the amine bands of LID (1650 and $1550 \mathrm{~cm}^{-1}$ ) present in the spectrum of physical mixture that disappear in the spectrum of the inclusion complex. The analysis of the inclusion products using DSC revealed the formation of the inclusion complex by the disappearance of the fusion endotherm of LID $\left(127-129^{\circ} \mathrm{C}\right)$ with the concomitant maintenance of the dehydration endotherms at around $158^{\circ} \mathrm{C}$ and $300^{\circ} \mathrm{C}$, typical of $\mathrm{M} \beta \mathrm{CD}$ (Figure 3). As reported in the literature, the ethanol competition with the guest molecule could also interfere in the formation of the inclusion complex, which strengthens the preferential use of water as solvent. ${ }^{31}$

The compatibility of the LID inclusion complexes with CHX was evaluated by the preparation of an aqueous solution of LID at $2.0 \% \mathrm{w} / \mathrm{w}$ or its equivalent within inclusion complexes with $\beta C D$ or $\mathrm{M} \beta C D$ mixed with $\mathrm{CHX}$ at $0.25 \% \mathrm{w} / \mathrm{w}$. Both complexes of LID showed an absence of turbidity over a 24-hour period. The noncomplexed control, consisting of an aqueous solution of LID in the presence of CHX, displayed turbidity and precipitation within 3 minutes. Over a 10-day period with agitation at room temperature, extensive precipitation was observed in control solutions. Solutions containing LID complexed with CDs maintained equivalent levels of CHX in filtrates after filtration, as seen in Table 4. These data clearly demonstrate that the inclusion of LID with CD effectively stabilized the presence of CHX in solution over time and permitted both drugs to be present together.

The higher solubility in water observed for the LID complexed with $\mathrm{M} \beta C D$ was the deciding factor to utilize these complexes to formulate a new gel. Three ingredients of each

Table 5 Formula proposed for the new LID and $\mathrm{CHX}$ gels and description of the functional classification of each excipient

\begin{tabular}{lll}
\hline Excipient & Excipient functionality/content (\%) & Characteristics \\
\hline Butylhydroxytoluene & Antioxidant/0.05 & Soluble in water and compatible with the drugs \\
Methylparaben & Preservative/0.1 & Soluble in water and compatible with the drugs \\
PEG 6000 & Thickener/2.0 & Soluble in water and compatible with the drugs \\
PEG-15 cocopolyamine & Mucoadhesive/2.0 & Soluble in water and compatible with the drugs \\
Hydroxyethylcellulose & Gelling/4.0 & Gels in aqueous solution and is compatible with the drugs
\end{tabular}

Abbreviations: $\mathrm{CHX}$, chlorhexidine gluconate; LID, lidocaine hydrochloride; PEG, polyethylene glycol. 
Table 6 Assay of drugs in the proposed formulation at time zero and after 6 months

\begin{tabular}{lll}
\hline Time & LID content (\%) & CHX content (\%) \\
\hline 0 & $98.8 \pm 0.04$ & $99.6 \pm 0.002$ \\
6 months & $98.6 \pm 0.04$ & $99.3 \pm 0.001$ \\
\hline
\end{tabular}

Note: Media \pm standard deviation of $\mathrm{n}=3$ determinations.

Abbreviations: $\mathrm{CHX}$, chlorhexidine gluconate; LID, lidocaine hydrochloride.

functional category needed for gel formation were tested for their compatibility with the drugs in aqueous solution and their compatibility percentages defined. These complexes were soluble or miscible with the additives, with no turbidity or precipitation observed in the solutions after 10 days under agitation. Table 5 presents the basic composition proposed for the formulation of the gel.
The final gel presented a slightly yellowish color and an LID content of $98.8 \% \pm 0.04 \%$ and a CHX content of $99.6 \% \pm 0.002 \%$. The $\mathrm{pH}$ measured was 5.8 , close to the optimum $\mathrm{pH}$ for a vaginal cream (3.5-4.5). The $\mathrm{pH}$ of greater stability for the drugs is between 3 and $6 .{ }^{6,32}$ An excellent stability was observed for the new formulation (Table 6), indicating its strong commercial viability.

In release studies, purified water was used as the acceptor solution. ${ }^{33-35}$ The CHX solubility determined in this medium was $200 \mathrm{mg} / \mathrm{mL}$, and for LID $166.4 \mathrm{mg} / \mathrm{mL}$. In order to ensure sink conditions, the volume of acceptor solution was fixed at $20.0 \mathrm{~mL}$. The sink condition was considered satisfactory since the drug concentrations in this medium was at least 10 times smaller than the experimental drug solubility, considering

A

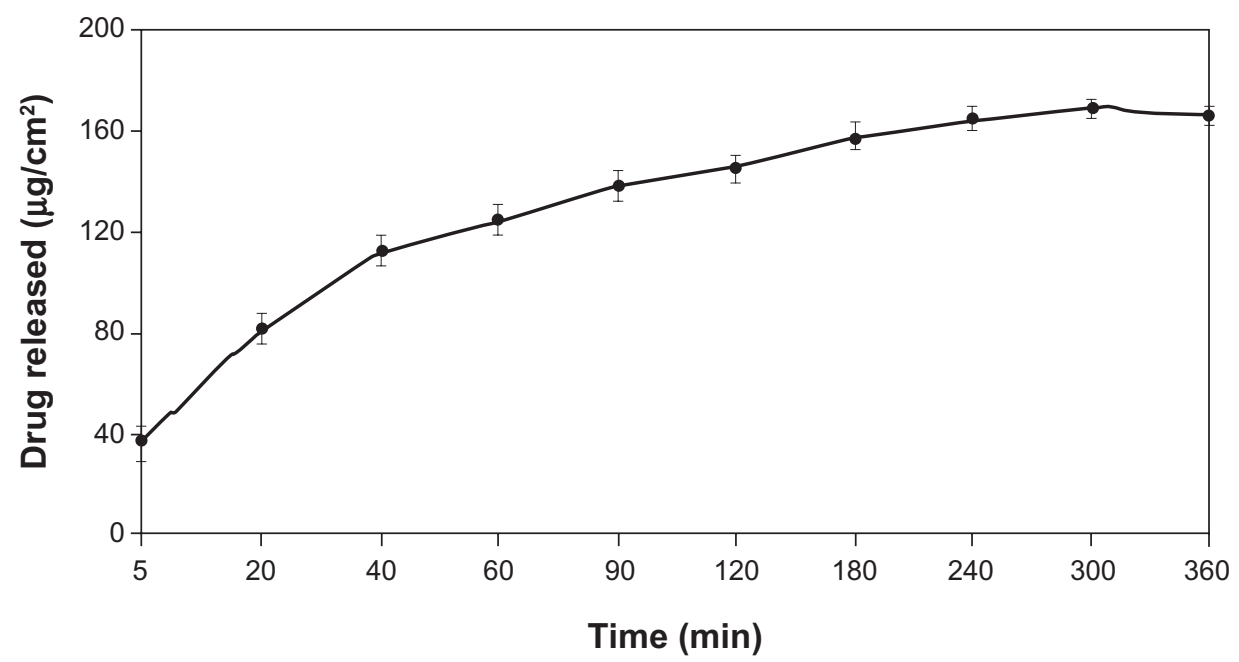

B

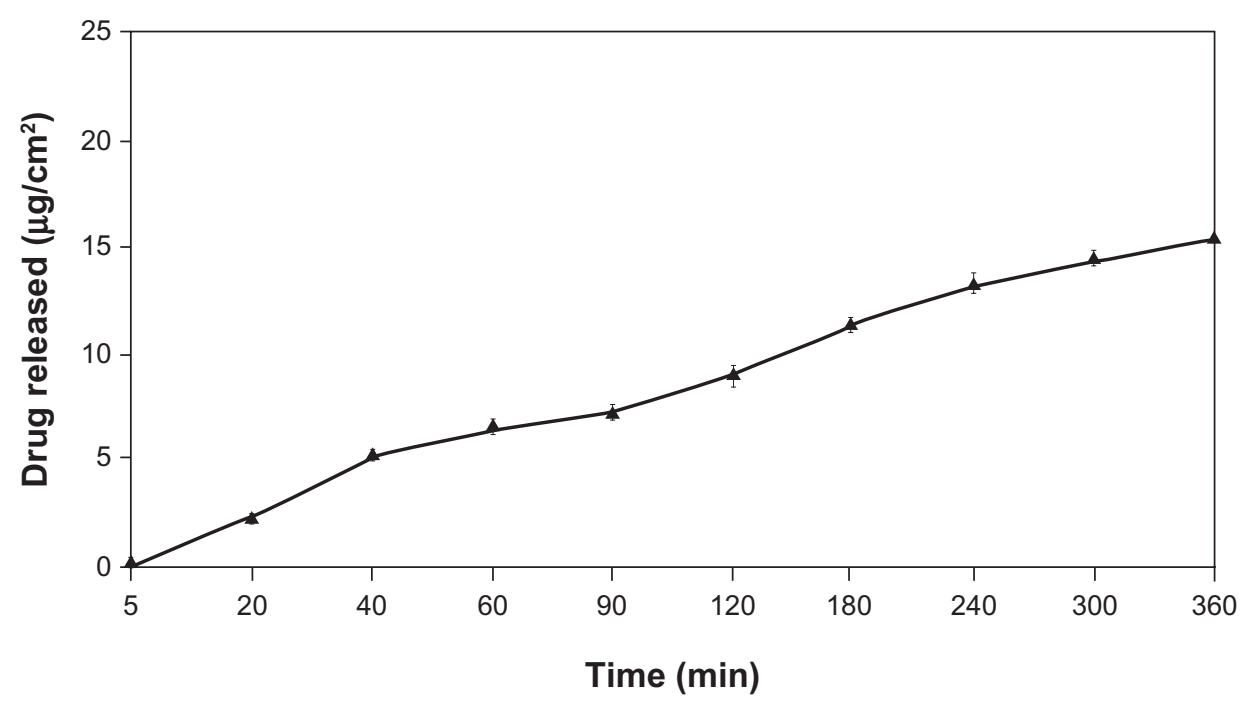

Figure 4 Amount of lidocaine hydrochloride $\mathbf{A})$ and chlorhexidine gluconate $\mathbf{B}$ ) released $\left(\mu \mathrm{g} / \mathrm{cm}^{2}\right)$ versus time (hours) from the proposed formulation $(\mathrm{n}=\mathrm{I}$ ). 
Table 7 Cumulative amounts of LID and $\mathrm{CHX}$ released from the formulation proposed in function of time in vitro release studies

\begin{tabular}{lcc}
\hline Time (min) & \multicolumn{2}{c}{ Cumulative amounts released $\left(\mu \mathrm{g} / \mathrm{cm}^{2}\right)$} \\
\cline { 2 - 3 } & LID $^{\mathbf{a}}$ & CHX $^{\mathbf{a}}$ \\
\hline 5 & $35.7 \pm 6.5$ & $0.24 \pm 0.13$ \\
20 & $81.2 \pm 6.2$ & $2.31 \pm 0.20$ \\
40 & $111.9 \pm 5.9$ & $5.22 \pm 0.27$ \\
60 & $123.8 \pm 6.3$ & $6.11 \pm 0.38$ \\
90 & $137.3 \pm 5.9$ & $7.29 \pm 0.36$ \\
120 & $144.7 \pm 5.9$ & $8.99 \pm 0.44$
\end{tabular}

Note: a Media \pm standard deviation of $\mathrm{n}=3$ determinations.

Abbreviations: $\mathrm{CHX}$, chlorhexidine gluconate; LID, lidocaine hydrochloride.

that all drugs in the donor compartment were released. Figure 4 and Table 7 show the in vitro release profiles over 6 hours using the formulations proposed. The results demonstrated that the drugs were released from the formulation. The release kinetics followed the Higuchi model $(\mathrm{r}>0.99)$. The flux $(J)$ was calculated from the slopes in the linear portion of the curves and was $6.196 \pm 0.49 \mu \mathrm{g} / \mathrm{cm}^{2} \cdot \mathrm{min}^{-1}$ for LID and $1.0 \pm 0.06 \mu \mathrm{g} / \mathrm{cm}^{2} \cdot \mathrm{min}^{-1}$ for CHX. ${ }^{36}$

Appropriate rheological properties were observed for the gel proposed, especially in terms of its ability to spread and to coat the urogenital mucosa. ${ }^{37}$ The rheograms presented in Figures 5 and 6 show that the formulation behaved as a nonNewtonian pseudoplastic fluid. The profiles of the rheograms showed an increase in shear stress with an increasing shear rate $\left(0.1\right.$ to $\left.100 \mathrm{~s}^{-1}\right)$ and a reduction of tension by reducing this rate $\left(100\right.$ to $\left.0.1 \mathrm{~s}^{-1}\right)$. Both present a nonlinear curve profile with a tendency to decrease the apparent viscosity of the formulation as a function of increasing shear rate. The classification of the formulation as a non-Newtonian fluid determines that the interactions between its components affect the rate of deformation caused by external forces, resulting in no proportionality between the rate $(\gamma)$ and shear stress $(\tau)$, as shown in Figure 5. ${ }^{38}$

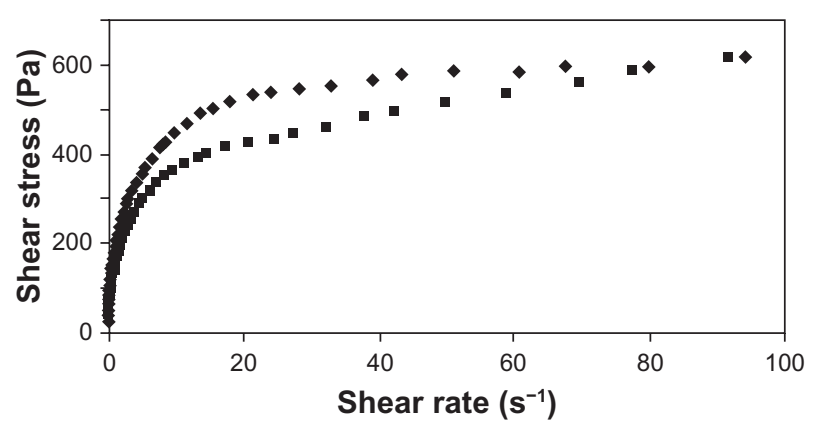

Figure 5 Rheogram of the proposed formulation showing shear stress versus shear rate rising from 0.1 to $100 \mathrm{~s}^{-1}$ (diamond) and decreasing from 100 to $0.1 \mathrm{~s}^{-1}$ (square).

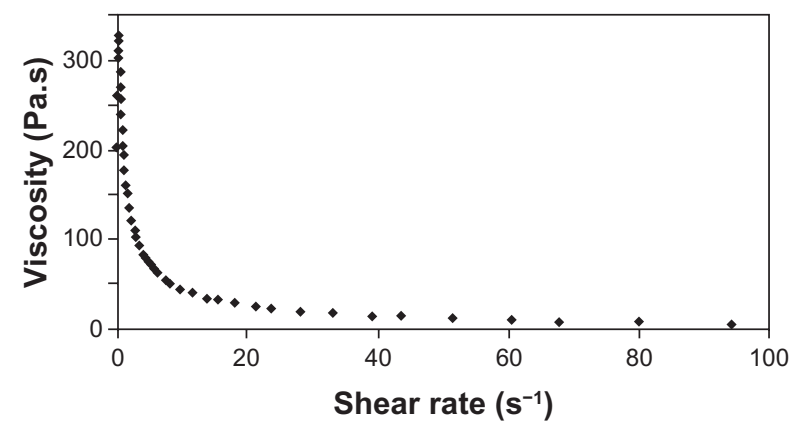

Figure 6 Rheogram of the proposed formulation showing apparent viscosity versus shear rate $\left(0.1\right.$ to $\left.100 \mathrm{~s}^{-1}\right)$.

The behavior exhibited by the new formulation corresponds to that obtained by Owen et al testing some commercial vaginal contraceptive gels. ${ }^{39}$ These gels, when subjected to rheological studies, were characterized as a non-Newtonian pseudoplastic fluid due to reduced viscosity of the formulation prepared against the increase of shear rate. By observing the flow index (n) of the formulation, which indicates the degree of resistance during the fluid flow, we measured a value of 0.4084 , which corresponds to a pseudoplastic formulation. The consistency index obtained was $151.4 \mathrm{~Pa} \cdot \mathrm{s}^{\mathrm{n}}$. These values of flow index and consistency index are consistent with those of the commercial contraceptive gels previously reported. ${ }^{39}$

The rheograms shown in Figure 7 demonstrate the dependence behavior of elastic modulus $\left(\mathrm{G}^{\prime}\right)$ and viscous modulus $\left(G^{\prime \prime}\right)$ in relation to frequency, ranging from 0.1 to $10.0 \mathrm{~Hz}$ with strain rate set at $5 \%$, characterized as a pseudogel.

Figure 8 describes the behavior of the apparent viscosity of the formulation over time when the shear rate was fixed at $10.0 \mathrm{~s}^{-1}$. The significant decrease in viscosity during the initial 30 seconds, with a relative standard deviation of $4.52 \%$, and the profile of this constant from the 30 -second test with a standard deviation of $1.18 \%$, provided further evidence to characterize the formulation as nonthixotropic.

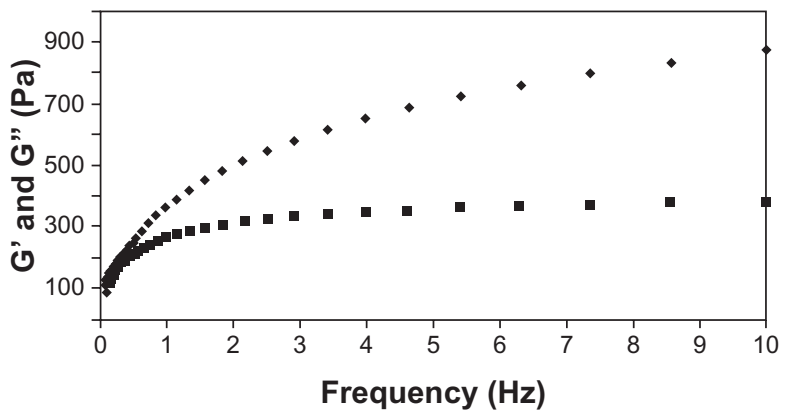

Figure 7 Rheogram of the proposed formulation showing the elastic modulus $\mathrm{G}^{\prime}$ (diamond) and viscosity modulus G" (square) versus frequency from 0.1 to $10.0 \mathrm{~Hz}$ with a fixed percentage of deformation. 


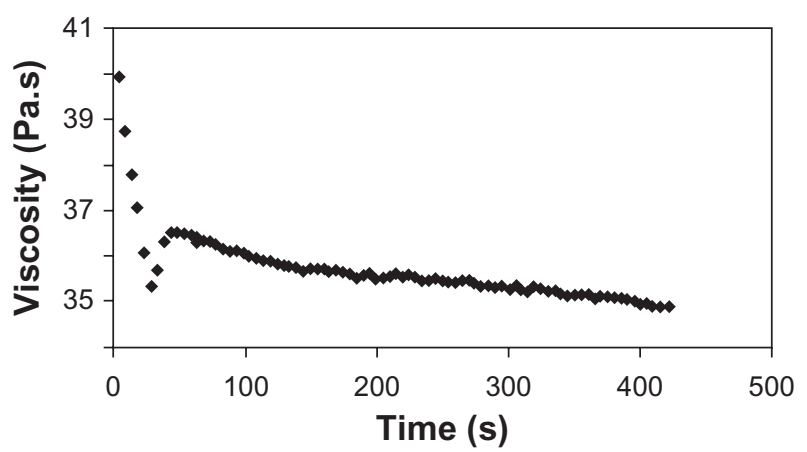

Figure 8 Rheogram of the proposed formulation showing apparent viscosity versus time with shear rate fixed at $10.0 \mathrm{~s}^{-1}$.

\section{Conclusion}

The analytical methodology presented here was validated for linearity, selectivity, precision, sensitivity, and accuracy to assure its suitablity for use in quantifying the concentrations of LID and CHX in the various formulations and their release from complexes in vitro. We conclude that LID and CHX are incompatible when present together in aqueous media. We circumvented this incompatibility by the inclusion of LID in $M \beta C D$, which enabled the formulation of a gel that presents both an analgesic and bactericide simultaneously. The inclusion of 2 mucoadhesive agents, hydroxyethylcellulose and PEG-15 cocopolyamine, creates a novel gel suitable for application to the physiological conditions of the urogenital cavities. The results presented here represent the first description of the inclusion of a salt of lidocaine into CDs, which points to the potential use of this technology in various other pharmacotechnical applications.

\section{Acknowledgments}

This work was supported by FAPERJ, CAPES Edital CAPES Nanobiotecnologia 2008 and CNPq. We are grateful to William Provance Jr for English review.

\section{Disclosure}

The authors report no conflict of interest in this work.

\section{References}

1. Doherty DW. Instillagel: an anaesthetic antiseptic gel for use in catherization. Br J Nurs. 1999;8(2):109-112.

2. Magera JS Jr, Inman BA, Elliott DS. Does preoperative topical antimicrobial scrub reduce positive surgical site culture rates in men undergoing artificial urinary sphincter placement? J Urol. 2007;178(4 Pt 1): 1328-1332.

3. Collins MK, Porter KB, Brook E, Johnson L, Williams M, Jevitt CM. Vulvar application of lidocaine for pain relief in spontaneous vaginal delivery. Obstet Gynecol. 1994;84(3):335-337.
4. Sperling H, Bastian HP, Boeminghau F, Ludwig G, Terhorst B, Rübben H. Local antiseptic therapy for non-gonococcal urethritis: phase II study with Instillagel. World J Urol. 200;20(1):45-47.

5. British National Formulary. 60th ed. London, UK: British Medical Association and Royal Pharmaceutical Society of Great Britain; 2010 .

6. Sweetman SC. Martindale: The Complete Drug Reference. 32rd ed. London, UK: The Pharmaceutical Press; 1999.

7. Moffat AC, Ossleton MD, Widrop B. 3rd ed. Clarke's Analysis of Drugs and Poisons. London: Pharmaceutical Press; 2004.

8. Lowe NJ, Shaath NA, Pathak MA. 2nd ed. Sunscreens: Developments, Evaluations and Regulatory Aspects. New York: Marcel Dekker, Inc; 1997.

9. Uekama K, Hirayama F, Irie T. Cyclodextrin drug carrier systems. Chem Rev. 1998;29(39):2045-2076.

10. Rajewski RA, Stella VJ. Pharmaceutical applications of cyclodextrins. In vivo drug delivery. J Pharm Sci. 1996;85(11):1142-1169.

11. Loftsson T, Brewster ME. Pharmaceutical applications of cyclodextrin I. Drug solubilization and stabilization. J Pharm Sci. 1996;85(10):1017-1025.

12. Brazilian Pharmacopoeia. 4th ed. São Paulo: Atheneu; 1998.

13. British Pharmacopoeia. London: Her Majesty's Stationery Office; 2010.

14. Xu Y, Wong GY. Simultaneous determination of lignocaine hydrochloride, chlorhexidine gluconate, and triamcinolone acetonide in suspension by reversed-phase HPLC. J Liq Chromatogr Relat Technol. 1999;22(13):2071-2091.

15. International Conference on Harmonization (ICH). Q2B Validation of Analytical Procedures: Methodology. US FDA Federal Register, 1997. http://www.fda.gov/downloads/Drugs/GuidanceComplianceRegulato ryInformation/Guidances/UCM073384.pdf

16. Scalia S, Villani S, Scatturin A, Vandelli MA, Forni F. Complexation of the sunscreen agent, butyl-Methoxidibenzoilmethane with hydroxypropyl $\beta$-cyclodextrin. Int J Pharm. 1998;175:205-213.

17. Scalia S, Molinari A, Casolari A, Maldotti A. Complexation of the sunscreen agent, phenylbenzimidazole sulphonic acid with cyclodextrins: effect on stability and photo-induced free radical formation. Eur J Pharm Sci. 2004;22(4):241-249.

18. Higuchi T, Connors KA. Phase-solubility techniques. In: Reilly C, editor. Advances in Analytical Chemistry and Instrumentation. New York: Wiley/Interscience; 1965:117-212.

19. Karpanen TJ, Worthington T, Conway BR, Hilton AC, Elliott TSJ, Lambert PA. Penetration of chlorhexidine into human skin. Antimicrob Agents Chemother. 2008;52(10):3633-3636.

20. Moreira TS, Sousa VP, Pierre MBR. A novel transdermal delivery system for the anti-inflammatory lumiracoxib: influence of oleic acid on in vitro percutaneous absorption and in vivo potential cutaneous irritation. AAPS Pharm Sci Tech, 2010;11(2):621-629.

21. Murillo Pulgarín JA, Alañón Molina A, Alañón MT. Direct determination of naftopidil by non-protected fluid room temperature phosphorescence. Analyst. 2001;126(2):234-238.

22. Basrani BR, Manek S, Sodhi RNS, Fillery E, Manzur A. Interaction between sodium hypochlorite and chlorhexidine gluconate. Basic Res Tech. 2007;33(8):966-969.

23. Rasimick BJ, Nekich M, Hladek MM, Musikant BL, Deutsch AS. Interaction between chlorhexidine digluconate and EDTA. J Endod. 2008;34(12):1512-1513.

24. Abdelmageed R, Labyad N, Watson DG, Pournamdari M, Cable CG, Stanley E. Evaluation of the stability of morphine sulphate in combination with Instillagel. J Clin Pharm Ther. 2008;33(3):263-271.

25. Franco CF, Pataro AL, Souza LCR, Santos VR, Cortés ME, Sinisterra RD. In vitro effects of a chlorhexidine controlled delivery system. Artif Organs. 2003;27(5):486-491.

26. Tatai A, Aigner Z, Erös I, Kata M. Preparation and investigation of mixtures containing lidocaine base and $\beta$-cyclodextrin. J Incl Phenom Macrocycl Chem. 2007;59(1-2):105-113. 
27. Mukne AP, Nagarsenker MS. Triamterene- $\beta$-cyclodextrin systems: preparation, characterization and in vivo evaluation. AAPS Pharm Sci Tech. 2004;5(1):Article 19.

28. Challa R, Ahuja A, Ali J, Khar RK. Cyclodextrins in drug delivery: an updated review. AAPS Pharm Sci Tech. 2005;6(2):E329-E357.

29. Brewster ME, Loftsson T Cyclodextrins as pharmaceuticals solubilizers. Adv Drug Deliv Rev. 2007;59(7):645-666.

30. Cal K, Centkowska K. Use of cyclodextrins in topical formulations: pratical aspects. Eur J Pharm Biopharm. 2008;68(3):467-478.

31. Wade A, Weller PJ. Handbook of Pharmaceutical Excipients. 3rd ed. London: Pharmaceutical Press; 1999.

32. Powell MF. Stability of lidocaine in aqueous solution: effect of temperature, $\mathrm{pH}$, buffer, and metal ions on amide hydrolysis. Pharm Res. 1987;4(1):42-45.

33. Ricci EJ, Lunardi LO, Nanclares DMA, Marchetti JM. Sustained release of lidocaine from poloxamer 407 gels. Int J Pharm. 2005;288(2): $235-244$.
34. Senel S, Ikinci G, Kas S, Yousefi-Rad A, Sargon MF, Hincal AA. Chitosan films and hydrogels of chlorhexidine gluconate for oral mucosal delivery. Int J Pharm. 2000;193(2):197-203.

35. Huang J, Wong HL, Zhou Y, Wu XY, Grad H, Komorowiski R. In vitro studies and modeling of a controlled-release device for root canal therapy. J Control Release. 2000;67(2-3):293-307.

36. Costa P, Lobo JMS. Modeling and comparison of dissolution profiles. Eur J Pharm Sci. 2001;13(2):123-133.

37. Chang JY, Oh YK, Choi HG, Kim YB, Kim CK. Rheological evaluation of thermosensitive and mucoadhesive vaginal gels in physiological conditions. Int J Pharm. 2002;241(1):155-163.

38. Gallegos C, Franco JM. Rheology of food, cosmetics and pharmaceuticals. Cur Op Inter Sci. 1999;4(4):288-293.

39. Owen DH, Peters JJ, Katz DF. Rheological properties of contraceptive gels. Contraception. 2000;62(6):321-326.
International Journal of Nanomedicine

\section{Publish your work in this journal}

The International Journal of Nanomedicine is an international, peerreviewed journal focusing on the application of nanotechnology in diagnostics, therapeutics, and drug delivery systems throughout the biomedical field. This journal is indexed on PubMed Central, MedLine, CAS, SciSearch $\AA$, Current Contents ${ }^{\circledR} /$ Clinical Medicine,

\section{Dovepress}

Journal Citation Reports/Science Edition, EMBase, Scopus and the Elsevier Bibliographic databases. The manuscript management system is completely online and includes a very quick and fair peer-review system, which is all easy to use. Visit http://www.dovepress.com/ testimonials.php to read real quotes from published authors. 